\title{
Prenatal Development of Retinogeniculate Axons in the Macaque Monkey during Segregation of Binocular Inputs
}

\author{
Cara J. Snider, ${ }^{1}$ Colette Dehay, ${ }^{2}$ Michel Berland, ${ }^{3}$ Henry Kennedy, ${ }^{2}$ and Leo M. Chalupa ${ }^{1}$ \\ 1 Section for Neurobiology, Physiology and Behavior, University of California, Davis, California 95616, 2/nstitut National de \\ la Santé et de la Recherche Médicale U371, Cerveau et Vision, 69500 Bron, France, and 'Faculté de Médecine Lyon \\ SUD, Service Gynecologie Obstetrique, 69495 Pierre Benite Cedex, France
}

In the fetal monkey the projections from the two eyes are initially completely intermingled within the dorsal lateral geniculate nucleus (DLGN) before separating into eye-specific layers (Rakic, 1976). To assess the cellular basis of this developmental process, we examined the morphological properties of individual retinogeniculate axons in prenatal monkeys of known gestational ages. The period studied spanned the time from when binocular overlap has been reported to be maximum, circa embryonic (E) day 77 through E112, when the segregation process is already largely completed in the caudal portion of the nucleus. Retinogeniculate fibers were labeled by making small deposits of Dil crystals into the fixed optic tract. After adequate time was allowed for diffusion of the tracer, fibers were visualized by confocal microscopy, and morphometric measures were made from photomontages. This revealed that retinogeniculate fibers in the embryonic monkey undergo continuous growth and elaboration during binocular overlap and subsequent segregation. Importantly, very few side-branches were found along the preterminal axon throughout the developmental period studied. Thus, restructuring of retinogeniculate fibers does not underlie the formation of eye-restricted projections in the primate. Rather, the results support the hypothesis that binocular segregation in the embryonic monkey is caused by the loss of retinal fibers that initially innervate inappropriate territories (Rakic, 1986).

Key words: retinogeniculate projections; primate; prenatal development; terminal arborizations; binocular segregation; dorsal lateral geniculate
The overlap and subsequent segregation of retinogeniculate projections was first demonstrated by Rakic (1976) by means of intraocular injections of tritiated amino acids in fetal monkeys. Since then, the intermingling and later sorting out of binocular inputs has been shown in many species, suggesting that this is a common feature of the mammalian visual system (Chalupa and Dreher, 1991). This developmental process could result from different cellular mechanisms, including the loss of retinal fibers, a retraction of retinogeniculate terminal arbors, and the elimination of axonal side-branches.

In the monkey, approximately 3 million ganglion cell axons are generated during fetal development, whereas only approximately 1 million survive to maturity (Rakic and Riley, 1983a). Moreover, the time course of fiber loss corresponds to the period when eye-specific projection patterns become established. This temporal correspondence suggests that the loss of retinal fibers that initially innervate inappropriate eye-specific territories within the geniculate anlage could be responsible for binocular segregation. This hypothesis is further supported by the finding that removal of one eye during the binocular overlap period results in a significant increase in the number of fibers in the remaining optic nerve and an expanded retinogeniculate projection from the remaining eye (Rakic and Riley, 1983b; Rakic, 1986).

There is also evidence for the restructuring of individual retinal fibers during early development. At the time when retinal

\footnotetext{
Received July 22, 1998; revised Oct. 7, 1998; accepted Oct. 9, 1998.

This work was supported by grants from Institut National de la Santé et de la Recherche Médicale, National Institutes of Health, and Human Frontier Science Program. We thank Jeff Quinto for excellent technical assistance.

Correspondence should be addressed to Dr. Leo M. Chalupa, Neurobiology, Physiology and Behavior, University of California, Davis, CA 95616.

Copyright (C) 1998 Society for Neuroscience $0270-6474 / 98 / 190220-09 \$ 05.00 / 0$
}

inputs from the two eyes are intermingled, retinogeniculate fibers in the fetal cat have been shown to possess numerous axonal side-branches, and this has lead to the conclusion that the formation of segregated retinogeniculate projections is caused by the resorption of these transient processes (Sretavan and Shatz, 1984, 1986). As yet, however, nothing is known about the morphological properties of retinogeniculate fibers during the formation of segregated inputs in the embryonic monkey.

A recent study dealing with the formation of magnocellular (M) and parvocellular (P) pathways has revealed a high degree of specificity in the formation of these two functional subsystems (Meissirel et al., 1997). By tracing individual DiI-labeled fibers, it was shown that the first retinal fibers, presumed to stem from the first-born $\mathrm{P} \beta$ ganglion cells (Rapaport et al., 1992), innervate the segment of the DLGN that will differentiate into the parvocellular laminae. Several weeks later, retinal fibers begin to grow into the portion of the DLGN that will form the magnocellular layers. This early divergence of $\mathrm{M}$ and $\mathrm{P}$ pathways appears to reflect the expression of distinct molecular markers on $\mathrm{P} \alpha$ and $\mathrm{P} \beta$ cells (Meissirel et al., 1997). As in the adult monkey retina (Xiang et al., 1995), two subpopulations of ganglion cells, presumably corresponding to $\mathrm{P} \alpha$ and $\mathrm{P} \beta$ ganglion cells, could be distinguished with Brn-3a and Brn-3b antibodies shortly after these neurons were generated.

In the present study we examined the innervation patterns and morphological properties of DiI-labeled retinogeniculate fibers with respect to the formation of eye-specific projection patterns. In particular, we were interested in determining whether retinal fibers in the developing monkey possess the axonal side-branches that have been described in the fetal cat during the binocular overlap period. For this purpose, we assessed the morphological 
properties of $\mathrm{M}$ and $\mathrm{P}$ retinogeniculate fibers from the period when retinal projections have been reported to be completely intermingled to the period when their ocular segregation is largely completed.

An abstract of these findings has been published previously (Snider et al., 1997).

\section{MATERIALS AND METHODS}

Cynomologus monkeys with controlled dates of impregnation provided four fetuses of known gestational ages at embryonic day (E) 77, E85, E95, and E112 (full term is at $165 \mathrm{~d}$ ). Pregnant monkeys were prepared for surgery under Alfatesine anesthesia. After intubation, anesthesia was continued with halothane in $\mathrm{N}_{2} \mathrm{O} / \mathrm{O}_{2}$ (70:30) mixture. Vital signs were monitored throughout the procedure. The fetuses were delivered by cesarean section, deeply anesthetized, and perfused transcardially with $0.9 \%$ saline followed by $4 \%$ paraformaldehyde fixative. All incisions were sutured, and the animals were medicated with an analgesic (Visceralgine intramuscular injection) before being returned to their cages. Visceralgine was continued twice daily for $48 \mathrm{hr}$. Additionally, an E50 fetal cat was used to obtain comparative information. The in utero surgical procedures for harvesting fetal cat tissue have been described in detail in previous publications (Williams et al., 1983; Chalupa et al., 1984).

Fiber labeling and histology. A small block of tissue including the optic tract and DLGN was isolated and embedded in 5\% agar. The block was then sectioned in the coronal plane (horizontal plane for cat) on a vibratome until the optic tract close to the DLGN was visible, and two small crystals of DiI (Molecular Probes, Eugene, OR) were implanted into the tract. Subsequently, the block was submerged in $4 \%$ paraformaldehyde and stored in the dark at $37^{\circ} \mathrm{C}$ to allow for passive diffusion of the DiI to the DLGN. After 1-4 months, the DLGN was sectioned at $200 \mu \mathrm{m}$ coronally for the monkey and horizontally for the cat, mounted on gelatinized slides, stained with $0.005 \%$ bizbenzimide to visualize the outline of the DLGN, and coverslipped.

Analysis. Labeled retinogeniculate axons were examined using a BioRad MRC-600 Scanning Confocal Microscope system equipped with an argon laser mounted on an Olympus microscope or a Leica Confocal Microscope System equipped with an argon and a krypton laser. An Olympus D Planapo $40 \times$ UV objective, with a numerical aperture of 0.85 , was used to collect optical sections in sequence as a function of tissue depth $(150-200 \mu \mathrm{m})$ by mechanically choosing the position of the microscope stage along the $z$-axis and recording an image at $2 \mu \mathrm{m}$ intervals to generate a $z$-series. Images of $768 \times 512$ pixels were obtained. These images were then compiled, and the $\mathrm{z}$-series was projected to obtain a view that was in focus throughout the entire labeled area. Photographic montages of retinogeniculate axons were constructed with several z-series projections (Adobe Photoshop 4.0) and printed using a Fujix Pictography 3000 printer.

In the monkey, measurements of terminal arbors, branch points within terminal arbors, and number of side-branches along the parent axon were calculated from confocal montages of retinogeniculate axons from various loci within the DLGN. Using Imagespace software, total terminal arbor lengths were calculated by measuring and adding all axon segments belonging to the terminal arborization. In the cat, side-branches were counted in 40 retinogeniculate axons (E47-postnatal day 2) using the data provided by Sretavan and Shatz (1986), their Figures 6 and 7, and three axons from an E50 fetal cat obtained from our colony. Using NIH Image software, the number of side-branches per millimeter of parent axon was calculated for both species.

\section{RESULTS}

The results are based on the morphometric analysis of 100 DiIlabeled retinogeniculate axons in fetal monkeys at four different ages: E77, E85, E95 and E112. These fibers were considered to be completely labeled, as evidenced by the presence of numerous growth cones, including fine caliber filopodia, on the distal ends. Typically, the preterminal portion of these axons extended for several hundred micrometers within the nucleus. With rare exceptions, the entry point from the optic tract could not be discerned because of the density of labeled fibers emanating from the tract. Although the laminar boundaries of the geniculate have

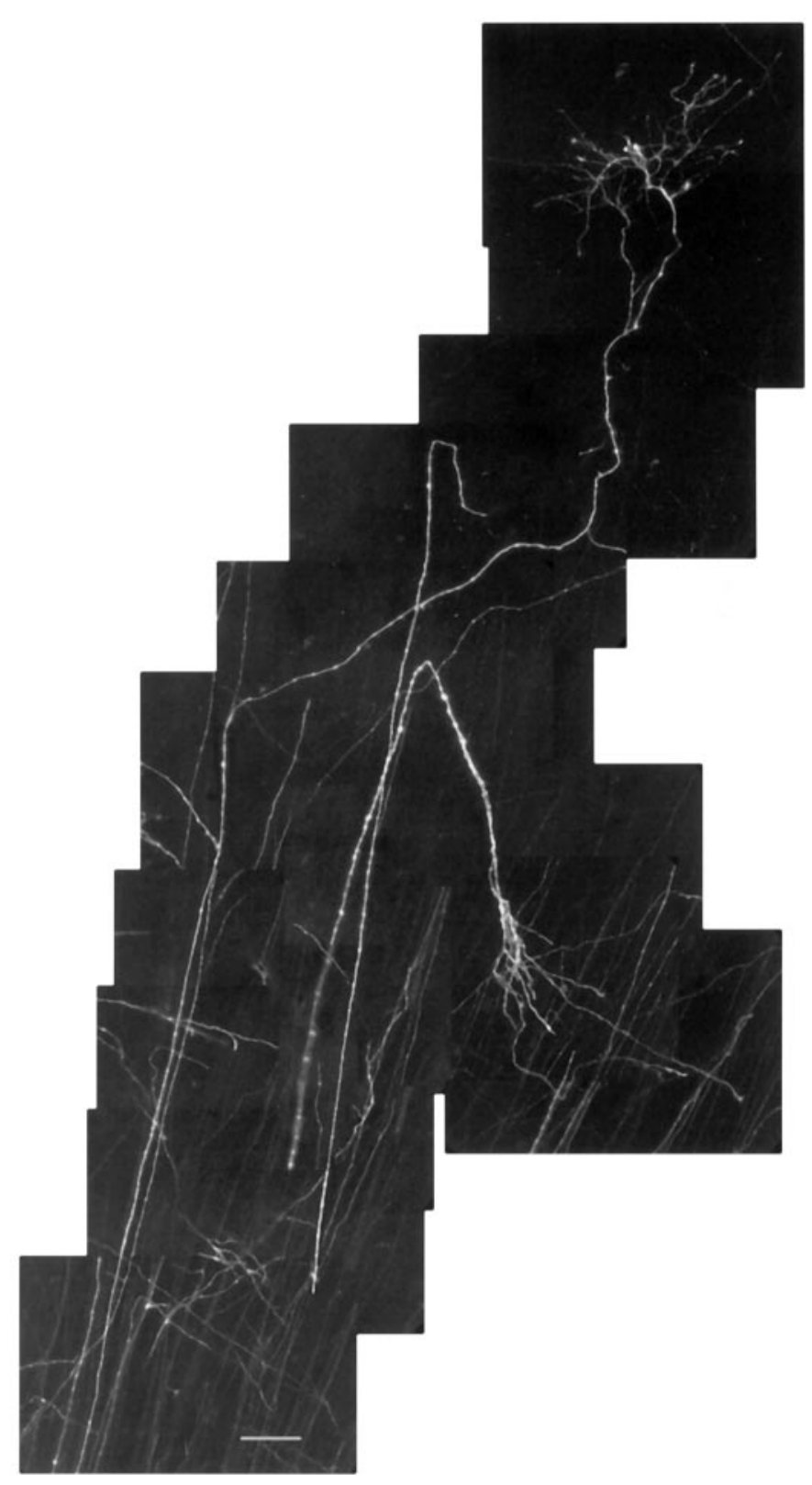

Figure 1. Confocal photomontage of retinogeniculate axons in the parvocellular segment of the monkey at E112. Note the lack of side-branches along the parent axons and the complexity of the terminal arborization. Scale bar, $50 \mu \mathrm{m}$.

yet to form (except in the caudal portion of the nucleus of the E112 monkey) in most cases, we were able to distinguish between fibers terminating in the magno and parvo segments based on the outside-to-inside temporal generation sequence of geniculate neurons and the known rotation of this structure (Rakic, 1976). The few fibers for which such a distinction could not be made were excluded from the overall sample.

Examples of DiI-labeled embryonic retinogeniculate axons from an E112 animal are shown in the photomontage depicted in Figure 1. Both of these fibers terminated in the parvocellular segment, but note the abrupt turn made by the lower axon. Such changes in trajectory were not uncommon in the overall sample of fibers we examined. This illustrative photomicrograph also shows that the terminal arbors are tipped by growth cones. This obser- 

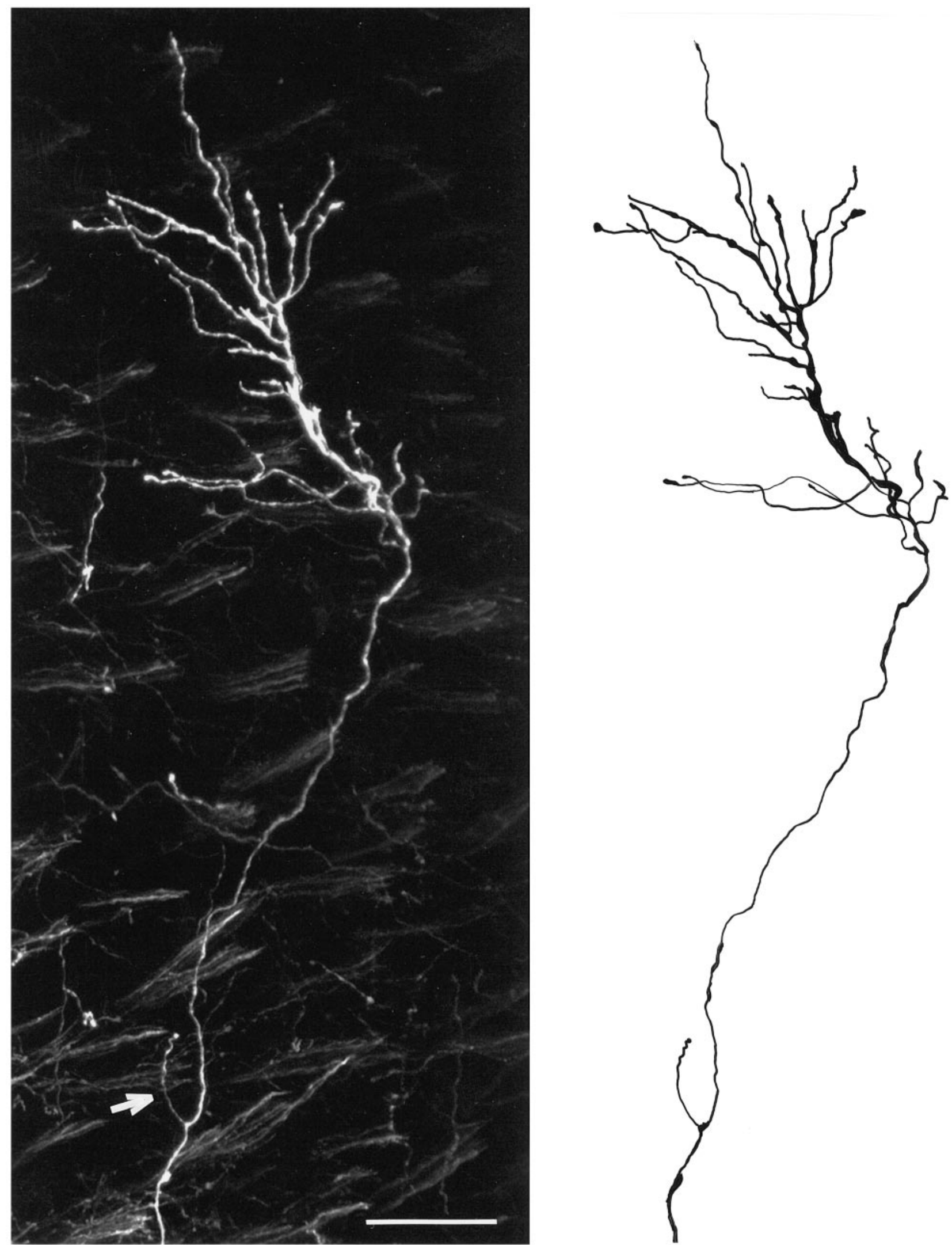

Figure 2. A confocal photomontage, left, and a corresponding drawing, right, of a retinogeniculate axon in the parvocellular segment of the monkey at E95. The white arrow points to a single side-branch emanating from the parent axon. Scale bar, $50 \mu \mathrm{m}$. 


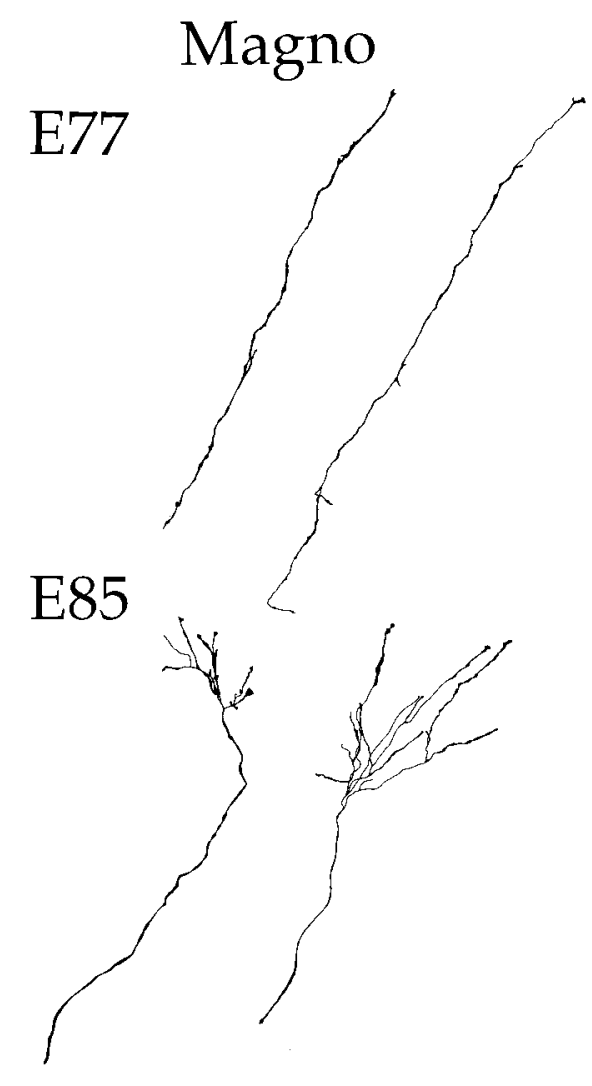

\section{Parvo}
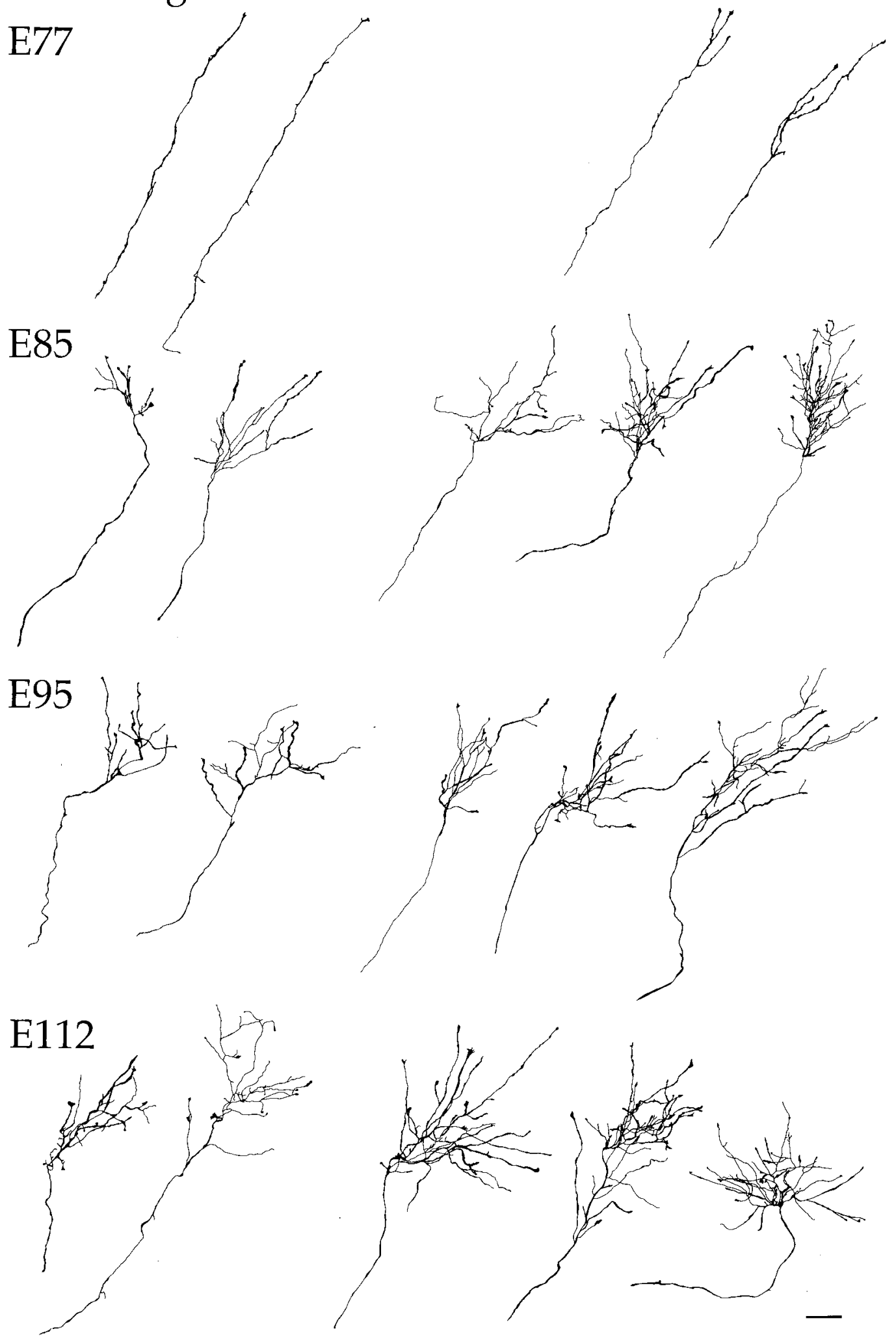

Figure 3. Tracings of reconstructed confocal photomontages of retinogeniculate terminal arbors in the fetal monkey at E77, E85, E95, and E112. Representative magnocellular (left side) and parvocellular (right side) arborizations are shown at each age. At E77, many magno axons have not yet formed terminal arbors, whereas the parvo axons have arborizations that are simple, with few branch points. Increasingly complex arborizations are seen at E85, E95, and E112 on both magno and parvo axons. Note that at all ages studied, the parvo axons have larger and more elaborate arborizations compared with magno axons. This developmental period encompasses the time during which initially intermingled retinal projections become segregated. Scale bar, $50 \mu \mathrm{m}$. 

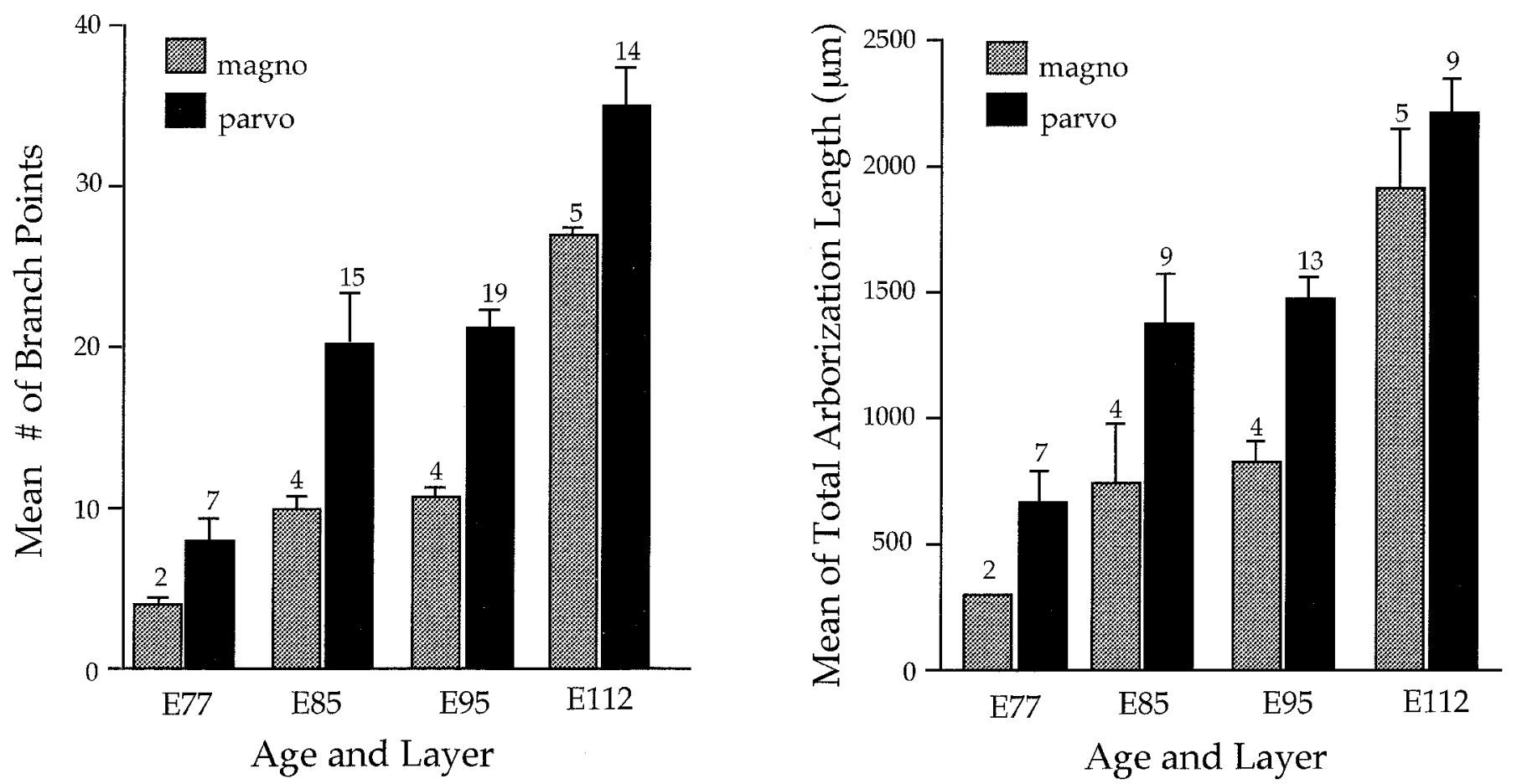

Figure 4. Analysis of terminal arborization complexity of single retinogeniculate axons in presumptive magnocellular (stippled) and parvocellular (black) layers. The left graph shows the mean number of branch points, and the right graph shows the mean total length of processes within the terminal arbor. The number of arbors analyzed is indicated on top of each bar, and the vertical brackets denote the SEM. Because it was not feasible in all cases to measure total arborization length, this sample is smaller than the sample of branch points.
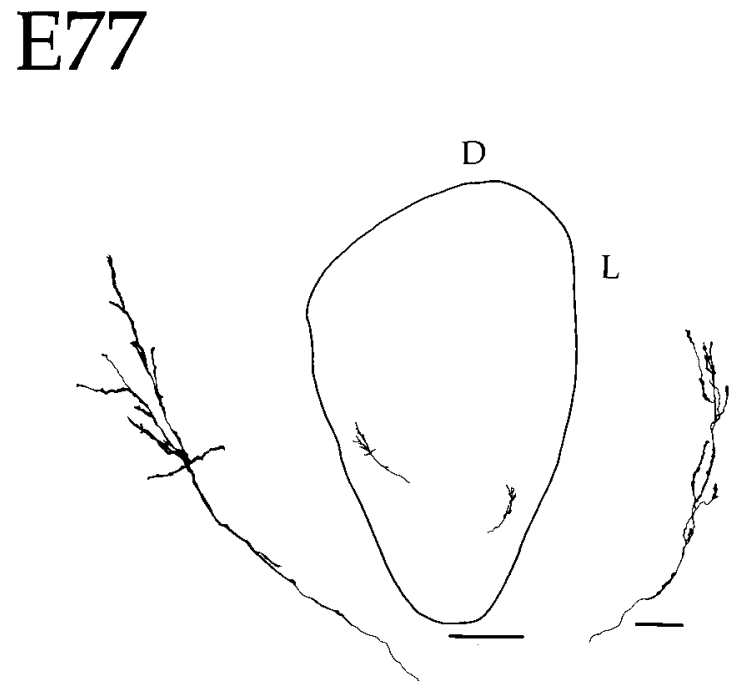
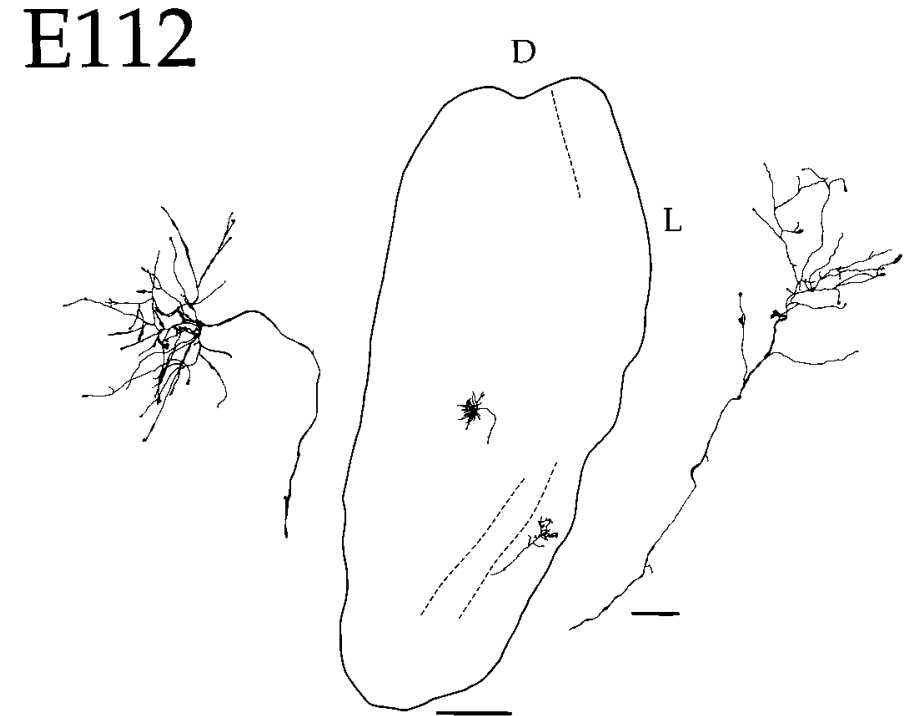

Figure 5. Drawings of $200 \mu \mathrm{m}$ coronal sections through the DLGN showing loci of reconstructed retinogeniculate axons at two fetal ages. To the left and right of each section an enlargement is shown of each arborization. At E77, no layers are present, and the terminal arbors are beginning to form. By E112, lamination has become apparent in the posterior pole of the DLGN (dotted line), and arbors are much more complex. Note that the terminal arbor at this age is within the boundary of a single layer. $D$, Dorsal; $L$, lateral. Scale bars: $50 \mu \mathrm{m}$ for enlarged individual axons; $500 \mu \mathrm{m}$ for sections.

vation implies that retinogeniculate terminals in the fetal monkey are still in a growth state, even at this relatively late stage. From such confocal images, drawings were made of retinal fibers as shown in Figure 2. Note the single axonal side-branch on this E95 $\mathrm{P}$ fiber, indicated by the arrow in the confocal image.

The change in structure of $\mathrm{M}$ and $\mathrm{P}$ retinal fibers during the course of development is illustrated in Figure 3. Here we depict drawings of comparable extents of the distal ends of these axons at different ages. At the earliest age studied (E77), most $\mathrm{M}$ fibers have yet to form terminal arbors, whereas the arbors of $\mathrm{P}$ fibers are beginning to be elaborated. At older ages, there is a progressive increase in the complexity and overall size of axonal arborizations, with $\mathrm{P}$ fibers continuing to show greater complexity than $\mathrm{M}$ fibers. As may be seen from the examples of $\mathrm{M}$ and $\mathrm{P}$ 


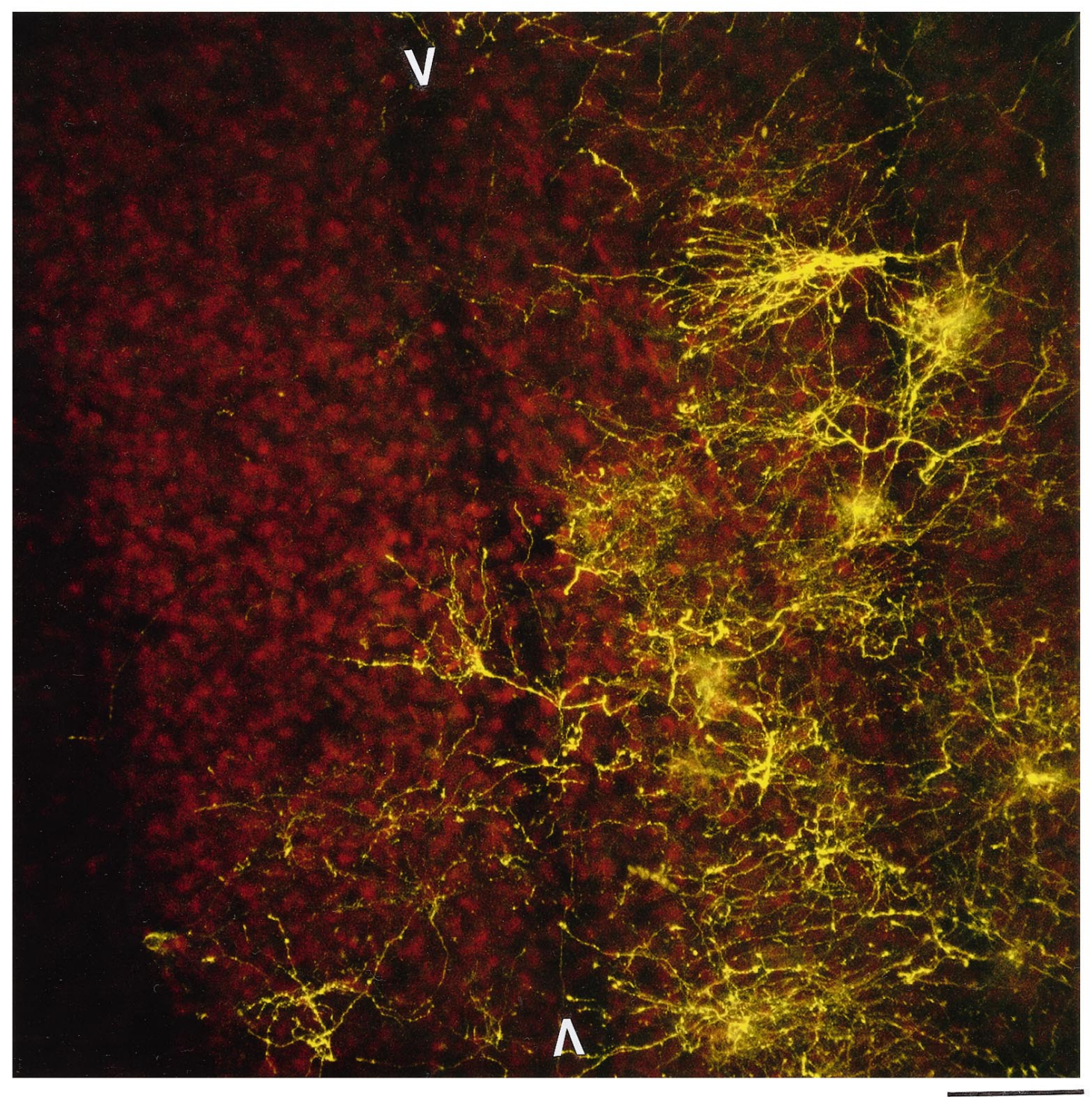

Figure 6. A confocal image of terminal arborizations in the caudal portion of the DLGN at E112. Note that at this age, the magnocellular layers have formed in this portion of the LGN (red cells) and that the arborizations ( yellow) are confined to a single layer. White arrows mark interlaminar zone. Scale bar, $100 \mu \mathrm{m}$. The colors of the image have been modified to enhance contrast.

fibers shown in Figure 3, the number of side-branches was no greater early in development than at later ages. Measurements of axonal branch points and total arborization length for a larger sample of $\mathrm{M}$ and $\mathrm{P}$ fibers are shown in Figure 4.

To gain a better perspective of arbor size in relation to the overall extent of the DLGN, Figure 5 compares the morphology of $\mathrm{M}$ and $\mathrm{P}$ fibers within the nucleus at E77 and at E112. In both cases, terminal arbors are confined to a clearly delimited region, and the extent of the territory innervated by each arbor remains relatively constant because of an increase in the size of the nucleus. A more striking illustration of the territorial restriction exhibited by retinogeniculate fibers is provided in the photomicrograph showing terminal arbors in the caudal portion of the geniculate in the E112 animal (Fig. 6). At this age, individual arbors are entirely confined to a single layer. Note that labeled arbors near the interlaminar zones do not protrude into adjacent layers. Rather, they seem to recognize a boundary, which appears to confine the growing tips of the terminal arbor growth cones to a given lamina. It should be emphasized that the DiI deposits were made into the optic tract, so we cannot distinguish between ipsilateral and contralateral fibers. Nevertheless, these observations indicate that geniculate laminar boundaries are recognized by retinal terminals in the primate very early in development. It is also the case that laminar formation does not appear to restrict arbor size, because the dimensions of terminals were similar in the rostral portion of the DLGN where layers had not yet formed (data not shown).

As may be discerned by inspection of the examples of retinogeniculate fibers shown in Figures 1, 2, 3 and 5, retinogeniculate axons in the embryonic monkey are virtually devoid of sidebranches throughout the developmental period studied. This was unexpected, because as noted above, such fibers in the fetal cat have been reported to have multiple axonal side-branches during the time when retinal inputs are intermingled within the DLGN (Sretavan and Shatz, 1984, 1986).

To quantify the incidence of axonal side-branches, we counted 


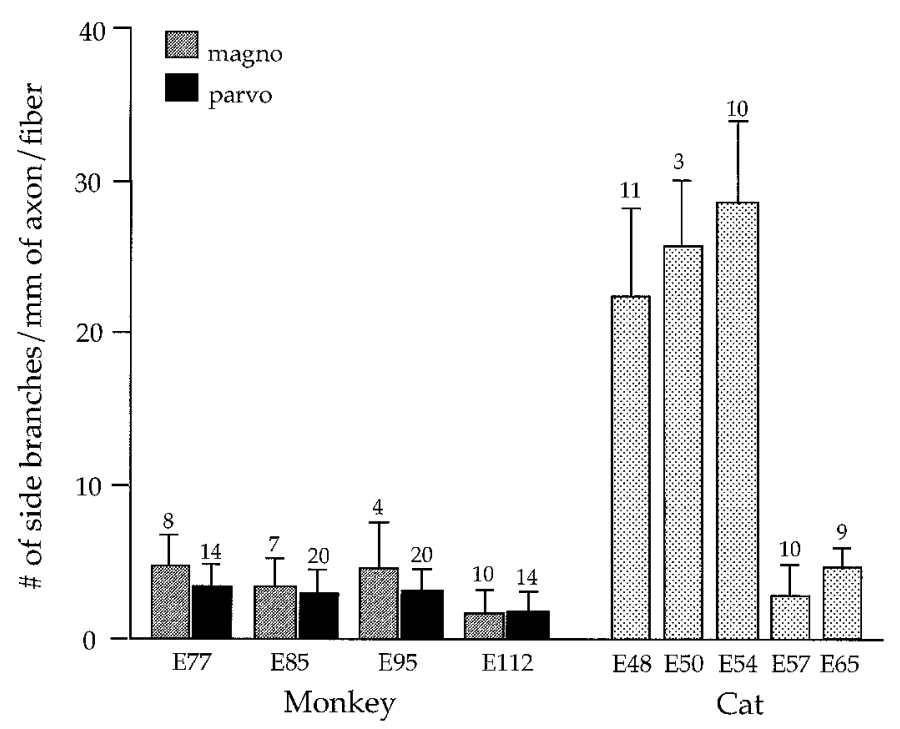

Figure 7. Comparison of the number of side-branches per millimeter of preterminal axon in monkey (magno, stippled bar; parvo, black bar) and in cat (dotted bar). The number of axons analyzed is indicated on top of each bar; standard error bars are shown. For each length of axon, the total number of side-branches was counted and divided by the total axon length of each fiber. Total axon length refers to the entire extent of a parent axon within the DLGN that could be visualized in a $200 \mu \mathrm{m}$ section. In cat, side-branches are prevalent at early fetal ages, dropping dramatically by E57. In monkey, side-branches on both parvo and magno axons are few and relatively constant during the time that eye-specific laminae are being formed. The fetal cat data at E48, E54, E57, and E65 are derived from Sretavan and Shatz (1986), their Figures 6 and 7, whereas the E50 data were obtained in our laboratory from DiI-labeled fibers.

such processes on the preterminal axon of $\mathrm{M}$ and $\mathrm{P}$ fibers at all of the ages that were studied. For purposes of comparison, similar counts were made from the illustrations of fetal cat retinogeniculate fibers provided by Sretavan and Shatz (1986), their Figures 6 and 7. We also analyzed fibers from an E50 cat, obtained from our colony, that were labeled and processed in a manner identical to the monkey, except for the horizontal plane of section.

The striking difference in the incidence of side-branches between the two species is illustrated in Figure 7. As may be seen, axonal side-branches in the embryonic monkey are few in number $(<4.5 / \mathrm{mm})$ and relatively constant during the period studied. In marked contrast, during the period of retinal overlap in the fetal cat (E47-E55), the number of retinogeniculate side-branches is high $(>25 / \mathrm{mm})$. By E57, when segregation of cat retinogeniculate projections is largely completed (Shatz, 1983), the incidence of such processes decreases to $<5 / \mathrm{mm}$. It is particularly noteworthy that the frequency of side-branches observed in the embryonic monkey during the period of binocular overlap (E64-E90) is equivalent to that present in the cat after the formation of eye-restricted projections (E57 and E65). Other pertinent comparisons between cat and monkey retinogeniculate fibers are provided in Table 1.

\section{DISCUSSION}

In this study we examined the morphological properties of retinogeniculate axons in the embryonic monkey, beginning at a time when the inputs from the two eyes have been reported to be completely intermingled and spanning the period when these projections become segregated into eye-specific layers. In the fetal monkey, retinal inputs have been reported by Rakic (1976) to be completely intermingled at E77 and E85, with ocular segregation beginning by E95 and being largely completed in the caudal portion of the DLGN by E112. We were especially interested in determining whether the segregation of initially intermingled left and right eye inputs in the primate involves the restructuring of single retinal fibers. If this were the case, one would expect to find the terminals of individual retinogeniculate fibers to be more extensive when the projections of the two eyes are overlapping than when they become segregated. This would be reflected by more extensive terminal arbors or a higher incidence of axonal side-branches during the period of binocular overlap, or both. It follows that the formation of eye-specific domains would then be attributable to the elimination of initially widespread axonal processes.

Our results clearly demonstrate that retinogeniculate fibers in the embryonic monkey undergo a process of continued growth and elaboration during binocular overlap and segregation. There was no evidence for retraction of terminal arbors or for the loss of transient axonal side-branches. The few axonal side-branches we did observe were relatively constant in number throughout development. Thus, we conclude that in the fetal macaque monkey some developmental factor other than the restructuring of axonal terminals and the elimination of side-branches must be responsible for the segregation of retinal inputs.

\section{Cell loss rather than axonal restructuring}

In monkey (Rakic and Riley, 1983a) and in humans (Provis, 1987), $>50 \%$ of optic nerve fibers are normally lost during the course of prenatal development, and the period of axon loss in the macaque corresponds to the time when eye-restricted projections are being formed. Furthermore, intraocular injections of anterograde tracers leads to labeling throughout the DLGN of monkeys that had one eye removed during the binocular overlap period (Rakic, 1981), and correspondingly, the remaining optic nerve of such enucleates has a higher than normal number of fibers (Rakic and Riley, 1983b). Taken together, our findings and the results of previous studies strongly suggest that in macaque monkey the formation of eye-specific projections reflects the loss of retinal fibers innervating inappropriate regions of the developing geniculate.

What might account for such fiber loss is unknown, although the results of prenatal monocular enucleation studies have been interpreted as demonstrating a role for binocular competition (Rakic, 1986). One possibility is that the terminal arbors that innervate inappropriate eye-specific territories might be at a competitive disadvantage, resulting in their subsequent elimination, presumably by an activity-mediated mechanism (Penn et al., 1998). In any case, the restriction of retinal arbors to single layers at E112 (Fig. 6) indicates that eye-specific laminar cues are expressed in the primate DLGN early in development, perhaps even before the beginning of the segregation process.

\section{Comparison of developing $\mathrm{M}$ and $\mathrm{P}$ fibers}

Our findings indicate that in the fetal monkey, $\mathrm{M}$ and $\mathrm{P}$ fibers exhibit a similar process of growth and elaboration, without any obvious sign of axonal restructuring. However, P retinogeniculate arbors form before $\mathrm{M}$ arbors, and the former also became more complex at earlier stages of development. This maturational difference between $\mathrm{M}$ and $\mathrm{P}$ pathways was evident throughout the development period studied. Presumably, this relates to the earlier generation of P ganglion cells (Rapaport et al., 1992) and the substantially earlier ingrowth of $\mathrm{P}$ fibers into the geniculate an- 


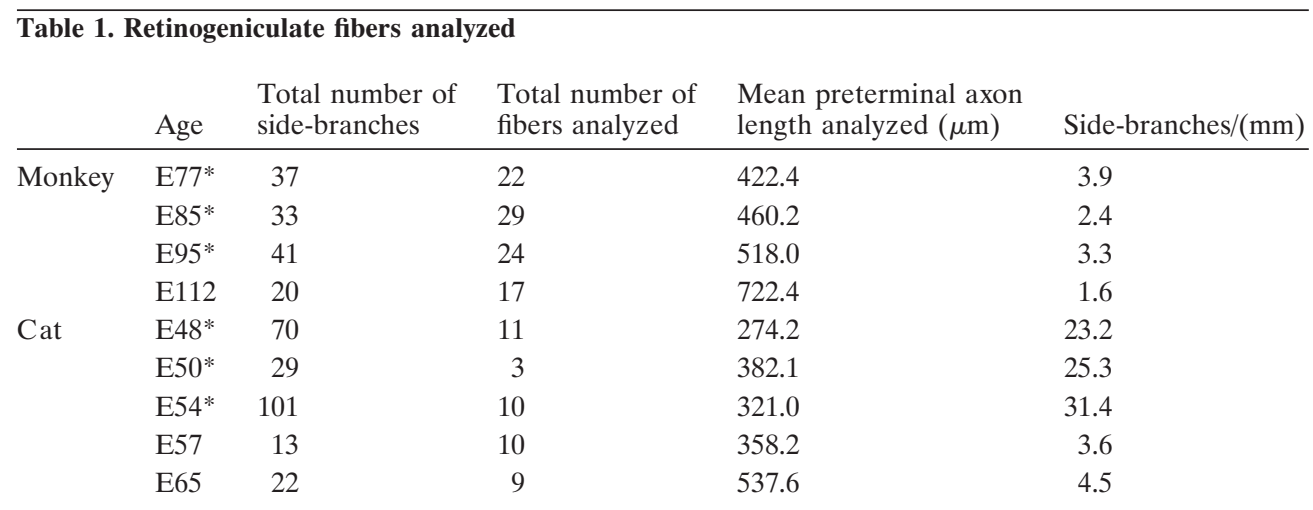

Asterisks indicate the ages during the binocular overlap period. Data for fetal cat at E48, E54, E57, and E65 were derived from Sretavan and Shatz (1986), their Figs. 6, 7. The side-branches/mm measure was derived by dividing the total number of side-branches at each fetal age by the product of number of fibers analyzed and the mean length of fibers analyzed $(\times 1000)$.

lage (Meissirel et al., 1997). By contrast, at maturity the overall extent and the complexity of $\mathrm{M}$ fibers are substantially greater than that of P fibers (Conley and Fitzpatrick, 1989). It would be of interest to determine when $M$ fibers begin their accelerated growth to surpass the dimensions of $\mathrm{P}$ fibers. In a postnatal study of $\mathrm{M}$ and $\mathrm{P}$ fibers in the galago, Lachica and Casagrande (1988) found that on the day of birth the two sets of retinal axons were basically indistinguishable on the basis of size and that it was only after several postnatal months that the $\mathbf{M}$ fibers exhibited an accelerated increase in size. As in the prenatal monkey, during the postnatal development of the galago, there was no indication of any resorption of axonal processes in either $\mathrm{M}$ or $\mathrm{P}$ fibers.

\section{Developmental differences between cat and macaque monkey}

The results reveal unexpected differences in the events underlying the formation of segregated retinogeniculate projections between the macaque monkey and the cat. What distinguishes the macaque from the cat is the paucity of axonal side-branches throughout the developmental period when eye-specific projections are being formed. It would be incorrect, however, to infer that primates and carnivores have evolved entirely different developmental strategies to form their eye-specific projections. Indeed, in both species the ingrowth of axons appears highly directed, and the formation of terminal arbors seems well defined. Moreover, in carnivores as in primates, there is a massive loss of optic fibers during the period when separation of left and right eye projections is occurring (Williams et al., 1986), and removal of one eye in a fetal cat during this period results in a significant increase in the number of optic fibers and retinal ganglion cells in the remaining eye (Williams et al., 1983; Chalupa et al., 1984). So why are axonal side-branches relatively common on retinogeniculate fibers of the fetal cat and so uncommon in the fetal monkey? Perhaps, this is related to the unique organizational features of the retinogeniculate pathway in the developing macaque monkey. One relevant factor may be that in the DLGN of this primate, laminar boundaries separate $\mathrm{M}$ and $\mathrm{P}$ pathways. Such an organization may place greater constraints on ingrowing retinogeniculate axons in the primate than in carnivores, where different cell classes are intermingled in the main laminae of the DLGN. Consequently, retinal axons in the fetal macaque might be more responsive to the molecular cues defining laminar boundaries because these specify cell type ( $\mathrm{M}$ or $\mathrm{P}$ ) as well as ocular domains (left or right). As yet, however, little is known about the factors that regulate the ingrowth of retinogeniculate axons in any species, so more study will be required to assess the validity of these suggestions.

It is important to note that the developmental pattern we observed in the macaque monkey may not be representative of other primate species. It has been known since the classic studies of Gordon Walls (1953) that the organization of retinogeniculate projections differs among primate species. We would expect developmental differences among primate species to be related to the degree to which both left/right eye inputs and the $\mathrm{M}$ and $\mathrm{P}$ pathways are segregated into distinct laminae at maturity. For this reason, it would be worthwhile to assess the prenatal development of retinal projections in other primates such as the squirrel monkey, which has been shown to have extensive intermingling of ocular inputs at maturity within the parvocellular laminae of the DLGN (Horton and Hocking, 1996).

\section{Concluding remarks}

The projections of the primate visual system at maturity are characterized by an exquisite degree of precision that accounts, in part, for the remarkable resolving power of this predominant sensory modality. The hallmark features distinguishing the anatomical organization of the primate visual pathways from those of other species have long been recognized. In recent years, a number of studies have also shown that the developmental events involved in forming key components of the primate visual system differ from those found in other species. In particular, it has been found that the retinal decussation pattern (Chalupa and Lia, 1991) as well as callosal projections in the striate cortex of the primate are highly precise throughout prenatal development (Dehay et al., 1988; Chalupa et al., 1989), with no evidence of the exuberance that has been documented in other species. What accounts for such differences in developmental specificity remains to be established, but it has been suggested that systems characterized by a high degree of precision at maturity require high precision "blueprints" during development (Chalupa and Dreher, 1991). This idea would seem to be supported by the ingrowth patterns and the paucity of axonal side-branches characterizing individual retinal fibers in monkey embryos. It seems reasonable to think that the events described here also take place during the formation of segregated retinal pathways in the human visual system. 


\section{REFERENCES}

Chalupa LM, Dreher B (1991) High precision systems require high precision "blueprints": a new view regarding the formation of connections in the mammalian visual system. J Cognit Neurosci 3:209-219.

Chalupa LM, Lia B (1991) The nasotemporal division of retinal ganglion cells with crossed and uncrossed projections in the fetal rhesus monkey. J Neurosci 11:191-202.

Chalupa LM, Williams RW, Henderson Z (1984) Binocular interaction in the fetal cat regulates the size of the ganglion cell population. Neuroscience 12:1139-1146.

Chalupa LM, Killackey HP, Snider CJ, Lia B (1989) Callosal projection neurons in area 17 of the fetal rhesus monkey. Dev Brain Res 46:303-308.

Conley M, Fitzpatrick D (1989) Morphology of retinogeniculate axons in the macaque. Vis Neurosci 2:287-296.

Dehay C, Kennedy H, Bullier J, Berland M (1988) Absence of interhemispheric connections of area 17 during development in the monkey. Nature 331:348-350.

Horton JC, Hocking DR (1996) Anatomical demonstration of ocular dominance columns in striate cortex of the squirrel monkey. J Neurosci 16:5510-5522.

Lachica EA, Casagrande VA (1988) Development of primate retinogeniculate axon arbors. Vis Neurosci 1:103-123.

Meissirel C, Wikler KC, Chalupa LM, Rakic P (1997) Early divergence of magnocellular and parvocellular functional subsystems in the embryonic primate visual system. Proc Natl Acad Sci USA 94:5900-5905.

Penn AA, Riquelme PA, Feller MB, Shatz CJ (1998) Competition in retinogeniculate patterning driven by spontaneous activity. Science 279:2108-2112.

Provis JM (1987) Patterns of cell death in the ganglion cell layer of the human fetal retina. J Comp Neurol 259:237-246.

Rakic P (1976) Prenatal genesis of connections subserving ocular dominance in the rhesus monkey. Nature 261:467-471.
Rakic P (1981) Development of visual centers in the primate brain depends on binocular competition before birth. Science 214:928-931.

Rakic P (1986) Mechanism of ocular dominance segregation in the lateral geniculate nucleus: competitive elimination hypothesis. Trends Neurosci 9:11-15.

Rakic P, Riley KP (1983a) Overproduction and elimination of retinal axons in the fetal rhesus monkey. Science 209:1441-1444.

Rakic P, Riley KP (1983b) Regulation of axon numbers in the primate optic nerve by prenatal binocular competition. Nature 305:135-137.

Rapaport DH, Fletcher JT, LaVail MM, Rakic P (1992) Genesis of neurons in the retinal ganglion cell layer of the monkey. J Comp Neurol 322:577-588.

Shatz CJ (1983) The prenatal development of the cat's retinogeniculate pathway. J Neurosci 3:482-489.

Snider CJ, Quinto JG, Dehay C, Berland M, Kennedy H, Chalupa LM (1997) Restructuring of retinogeniculate axons plays a minor role in the formation of eye-specific layers in the DLGN of the fetal monkey. Soc Neurosci Abstr 23:1159.

Sretavan DW, Shatz CJ (1984) Prenatal development of individual retinogeniculate axons during the period of segregation. Nature 308:845-848.

Sretavan DW, Shatz CJ (1986) Prenatal development of retinal ganglion cell axons: segregation into eye-specific layers within the cat's lateral geniculate nucleus. J Neurosci 6:234-251.

Walls GL (1953) The lateral geniculate nucleus and visual histophysiology. In: University of California studies in physiology, vol 9, no 1. Berkeley, CA: University of California.

Williams RW, Bastiani MJ, Chalupa LM (1983) Loss of axons in the cat optic nerve following fetal unilateral enucleation: an electron microscope analysis. J Neurosci 3:133-144.

Williams RW, Bastiani MJ, Lia B, Chalupa LM (1986) Growth cones, dying axons and developmental fluctuations in the fiber population of the cat's optic nerve. J Comp Neurol 246:32-69.

Xiang M, Zhou L, Macke J, Yoshioka T, Hendry SHC, Eddy R, Shows TB, Nathans J (1995) Genesis of neurons in the retinal ganglion cell layer of the monkey. J Neurosci 15:4762-4785. 